\title{
Extreme Lateral Infrajugular Transchondylar Versus Far Lateral Approach in 92 Patients, Indications and Outcome: 11 Years of Experience
}

ISSN: 2637-7748

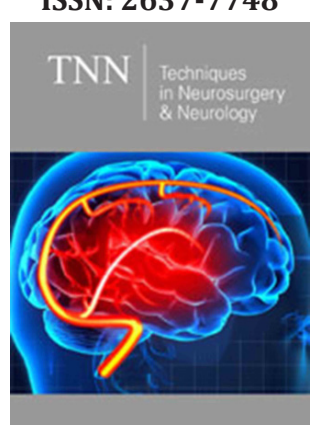

*Corresponding author: Mohammed Awad Elzain, Department of Neurosurgery, KSA

Submission: 侮April 13, 2020

Published: 䘜 December 22, 2020

Volume 3 - Issue 5

How to cite this article: Mohammed Awad Elzain, Rami Darwazeh, Michael Levy. Extreme Lateral Infrajugular Transchondylar Versus Far Lateral Approach in 92 Patients, Indications and Outcome: 11 Years of Experience. Tech Neurosurg Neurol. 3(5). TNN. 000575. 2020.

DOI: $10.31031 /$ TNN.2020.03.000575

Copyright@ Mohammed Awad Elzain, This article is distributed under the terms of the Creative Commons Attribution 4.0 International License, which permits unrestricted use and redistribution provided that the original author and source are credited.

\author{
Mohammed Awad Elzain ${ }^{1}$, Rami Darwazeh ${ }^{2}$ and Michael Levy ${ }^{3}$ \\ ${ }^{1}$ Department of Neurosurgery, King Abdullah Hospital Bisha, KSA \\ ${ }^{2}$ Department of Neurosurgery, Chongqing Medical University, China \\ ${ }^{3}$ Rady Children's Hospital, Department of Neurosurgery, USA
}

\section{Abstract}

Introduction: Brainstem tumors are among the most difficult to treat for most neurosurgeons.

Material and Method: We performed a retrospective study for all patients operated through far lateral $(n=65 / 92)$ or extreme lateral infra-jugular transchondylar (ELITE) $(n=27 / 92)$ approaches in the period between January 2003 through May 2014 in Rady Children's Hospital, San Diego, USA. Most patients were followed for an average of 5 years. The data were then analyzed and interpreted using SPSS version 20.

Result: The average age at presentation was 10 years \pm 8 months. Male and Female ratio was approximately 1:1. Wide range of pathologies were operated using far lateral or ELITE approaches including astrocytoms with different grades, arachnoid cysts, AT/RT, lymphomas, ependymomas, neurofibromas, epidermoid cysts, hemangiomas, meningiomas, medulloblastomas, mets, osteosarcoma, cholesteatoma, Rhabdomysarcoma, aneurysms and vertebral artery dissection. Gross total surgical resection was achieved in $63 \%(n=58 / 92), 4$ patients $(4.3 \%)$ had cyst fenestration for the arachnoid cysts, 1 bypass and 1 clipping for the vascular malformations. Postoperative new neurological deficits were encountered in 22 patients $(23.9 \%)$ and in most of the patients it was transient and resolved during follow up. Seventy-three patients (79.4\%) improved or cured, 14 deteriorated (15.2\%), 1 had recurrence (1.1\%) and 4 died (4.3\%). DISCUSSION: Far lateral approach or extreme lateral approach was early described and utilized for several foramen magnum tumors and vascular malformations lateral and anterolateral to the brain stem since the 1980s. This approach enables complete removal of pathologies lateral and ventrolateral to the brainstem.

Conclusion: Far lateral approach or Extreme Lateral Transchondylar approach provides safe trajectory wide range of benign, malignant as well as vascular malformations. The complications related to this approach are the same if not less than those described for other approaches to lesions in this area with the added benefits of complete respectability and less postoperative cranial nerve palsies. This ensures less recurrence rates after surgical resection, favorable outcome and long-term survival for most of the patients. This approach can be effective for children as well as adults harboring difficult posterior fossa pathologies with less postoperative mortalities and morbidities.

Keywords: Far lateral approach; Extreme lateral transchondylar approach; Long-term outcome

\section{Introduction}

Brainstem tumors are among the most difficult to treat for most neurosurgeons specially in pediatric patients for their deep locations and for being surrounded with the critical cardiorespiratory centers, cranial nerves and their nuclei, major ascending and descending tracts as well as the reticular formation. For this reason, many clinical and cadaveric studies have been done worldwide to detect the best and safest approach to brainstem lesions at different locations. Sergio et al in 2015 described what he called the safe entry zones to different brainstem lesions based on the lesion location. He subdivided the brainstem into different regions. Three for the midbrain (anterior, central and posterior) and two for the pons and medulla (each poses anterior and posterior regions). 
Anterior midbrain lesions can be approach through transcollosal, interfornicial, transchoroidal, transforaminal, pterional, orbitozygomatic and subtemporal transtentorial approaches based on the tumor extension. Central midbrain lesions can be approached through telovelar or infratentorial supracerebellar approaches. Most of lesions in the posterior midbrain are benign and tend to present mainly with hydrocephalus which is best treated by ETV. Endoscopic biopsy to this region should be avoided for the risk of 3rd ventricular hemorrhage and should be followed with serial imaging studies and if the lesion increased in size, then it can be approached through supracerebellar infratentorial or occipital transtentorial approaches. The safe entry zones described by the author to the midbrain include infracollicular (between the inferior colliculus and the 4th nerve), supracollicular (above the superior colliculus and should be limited by the aqueduct), perioculomotor area and through lateral mesencephalic sulcus. Lesions in the anterior pons can be approached through orbitozygomatic or presegmoid approaches with the safe entry zones being the supratrigeminal ( $4 \mathrm{~mm}$ vertical incision between the ponto-mesencephalic sulcus and trigeminal nerve just below the exit of 3rd cranial nerve) and peritrigeminal incision (anterolateral between the 5 th and 7 th cranial nerves) [1-8].

Posterior pons lesions can be accessed through telovelar approach and the safe entry zones include the suprafacial triangle (bounded medially by the median sulcus, laterally by the superior cerebellar peduncle and inferiorly by the facial colliculus) and the infrafacial triangle (bounded medially by the median sulcus, inferiorly by the striae medullaris and laterally by the facial nerve). Lesions at the anterior medulla are best approached through far lateral approach with the safe entry zones being the post-olivary sulcus (between the olive and the inferior cerebellar peduncle) and for posterior medullar midline through the posterior median sulcus. Far lateral approach was first described by Heros RC in 1986. He described it as a modification for the unilateral suboccipital approach in order to be able to reach vertebral artery aneurysms and vertebrobasilar junction through more drilling to the extreme lateral rim of foramen magnum into the condylar fossa together with $\mathrm{C} 1 \mathrm{arch}$. His approach had been further popularized and used by George et al in 1988 . He reported that it provides a safe trajectory to the anterior part of foramen magnum with less risk to the lower brainstem and cranial nerves injury.

It has been found that it is useful and safe to use this approach for anterior lower brainstem (medullary or cervicomedullary) lesions, but it needs a good anatomical knowledge for the extrinsic and intrinsic brainstem pathways, high resolution operative microscope, fine micro neurosurgical instruments and fine tip ultrasonic aspirator. For this, far lateral approach; also named extreme lateral approach; enables complete resection of most intradural extramedullary lesions like meningioma and neurofibroma without retraction on the brainstem or the spinal cord5. Also, it provides a good alternative to the anterolateral extrapharyngeal and midline transoral approaches with excellent wide exposure and less postoperative complications. This approach was further found to be useful for resection of posterolateral midbrain lesions and can be further extended by adding small incision to the tentorium [9-15].

Far lateral approach can also be further extended by resecting one third of the occipital condyle. This extends the angle of view to the anterior brainstem by about 15 degrees without affecting the craniovertebral junction stability even if it is done bilaterally. Also, it can be performed in children with the same efficacy. Far lateral approach with transcondylar exposure can give an extended anterolateral view to the lower clivus, foramen magnum and craniocervical junction in which craniocervical fixation is rarely needed. Besides, it gives the surgeon wider corridor with less retraction on the brainstem which can enables a complete resection of most lesions-even for difficult and complicated vascular lesions like arteriovenous fistula and posterior circulation aneurysms-with less cranial nerves neuropathies.3;10-13 Most of neurenteric cysts in the cervicmedullary regions can also be safely approached through far lateral transcondylar approach. Patel et al used this approach alone and in combination with other skull bases approaches to resect glomus jugulare tumors. He stated that it enables early control of the ICA and facilitates complete removal of posterior fossa, clivus and cavernous sinus extensions of the tumor. In this study, we would like to convey our experience in dealing with different pathologies through extreme lateral approach with and without transchondylar extension.

\section{Material and Method}

We performed a retrospective study for all patients operated through far lateral $(n=65 / 92)$ or extreme lateral infra-jugular transchondylar $(n=27 / 92)$ approaches in the period between January 2003 through May 2014 in Rady Children's Hospital, San Diego, USA. All patients were operated by the senior author (Dr. Michael Levy) and were followed for an average of 5 years. Data were collected through the computerized medical records and were followed in the clinic by the senior author himself. The data were then analyzed and interpreted using SPSS version 20 .

\section{Result}

In the period from January 2003 through May 2014, the senior author (Dr. Michael Levy) has operated upon 92 patients with different pathologies through either far lateral approach $(n=65 / 92)$ or Extreme Lateral Infra-jugular Transchondylar approach $(n=27 / 92)$ (ELITE) [16-22].

\section{Age distribution}

Table 1: The statistics of patients' age in months.

\begin{tabular}{|c|c|}
\hline Mean & 119.58 \\
\hline Median & 104.5 \\
\hline Mode & $156 \mathrm{a}$ \\
\hline Std. Deviation & 96.039 \\
\hline Minimum & 9 \\
\hline Maximum & 655 \\
\hline \multicolumn{2}{|c|}{ Multiple modes exist. The smallest value is shown } \\
\hline
\end{tabular}

The youngest patient in this series was 9 months old and the oldest was 54.6 years old with an average presentation at 10 
years \pm 8 months (Table 1 ). For the ease of description, patients were divided into groups based on the age. It was noted that most patients were aging more than 10-18 years. Almost all patients were children with only few older than 18 years $(n=7,7.6 \%)$ (Table 2; Figure 1).

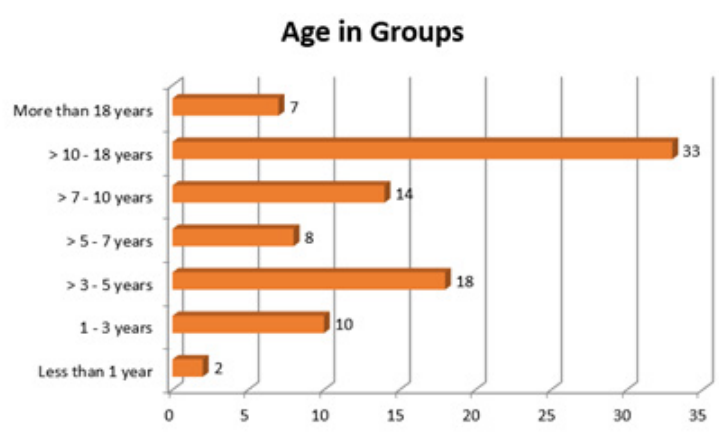

Figure 1: Age distribution in groups.

\section{Surgery type}

Patients were divided into 2 major groups based on the type of surgery:

a) Primary group: In which the patients had the surgery for the first time.

b) Subsequent group: In which the patients had the surgery for the same recurrent pathology either in our hospital or somewhere else (Figure 2).

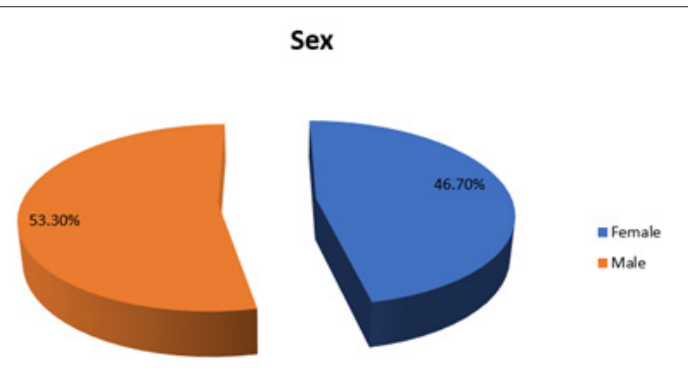

Figure 2: The sex distribution of the patients in the study.

Table 2: Age distribution in groups.

\begin{tabular}{|c|c|c|}
\hline Age in Groups & Frequency & Percent \\
\hline Less than 1 year & 2 & 2.2 \\
\hline 1 - 3 years & 10 & 10.9 \\
\hline$>3$ - 5 years & 18 & 19.6 \\
\hline$>5$ - 7 years & 8 & 8.7 \\
\hline$>7$ - 10 years & 14 & 15.2 \\
\hline$>10$ - 18 years & 33 & 35.9 \\
\hline More than 18 years & 7 & 7.6 \\
\hline Total & 92 & 100 \\
\hline
\end{tabular}

There were 89 patients in the primary group (Table 3; Figure 3 ) and for the remaining 3 patients (subsequent group), the pathologies were: medulloblastoma in 2 patients and GBM in one patient. The pathologies for the primary group were described in Table 2
Table 3: The histopathologies of the patients in the primary group.

\begin{tabular}{|c|c|c|}
\hline Pathologies & Frequency & Percent \\
\hline Anaplastic astrocytoma III & 1 & 1.1 \\
\hline Arachnoid cyst & 5 & 5.6 \\
\hline Astrocytoma grade II & 1 & 1.1 \\
\hline ATRT & 2 & 2.2 \\
\hline AVM & 3 & 3.4 \\
\hline B cell lymphoma Rt parietal & 1 & 1.1 \\
\hline Chiari & 1 & 1.1 \\
\hline Dysplastic cerebellar tissue & 1 & 1.1 \\
\hline Ependymoma II & 7 & 7.9 \\
\hline Ependymoma III & 7 & 7.9 \\
\hline Epidermoid Cyst & 1 & 1.1 \\
\hline Facial neurofiboma & 1 & 1.1 \\
\hline GBM & 2 & 2.2 \\
\hline GBM cerebellum & 1 & 1.1 \\
\hline Hemangioblastoma & 1 & 1.1 \\
\hline Medulloblastoma & 16 & 18 \\
\hline Medulloblastoma IV & 1 & 1.1 \\
\hline Meningioma & 1 & 1.1 \\
\hline Metastatic Retinoblastoma & 1 & 1.1 \\
\hline Necrotic Tissue in the pons & 1 & 1.1 \\
\hline Neurofibroma & 1 & 1.1 \\
\hline Osteomyelitis & 1 & 1.1 \\
\hline Osteosarcoma & 2 & 2.2 \\
\hline Petrous Cholesteatoma & 1 & 1.1 \\
\hline PICA aneurysm & 1 & 1.1 \\
\hline Pilocytic Astrocytoma & 21 & 23.6 \\
\hline Pontine glioma & 2 & 2.2 \\
\hline Rhabdomyosarcoma & 1 & 1.1 \\
\hline Schwannoma & 1 & 1.1 \\
\hline VA dissection & 1 & 1.1 \\
\hline Vestibular schwannoma & 2 & 2.2 \\
\hline Total & 89 & 100 \\
\hline
\end{tabular}

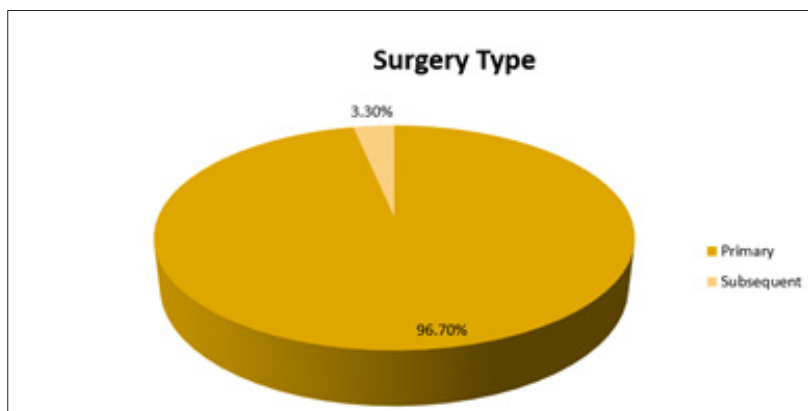

Figure 3: The surgery type done to handle the pathology.

\section{Surgical resection rate}

Most patients underwent gross total resection (63\%). Among the 4 patients (4.3\%) who underwent biopsy: 2 patients had 
diffuse pontine lesions and the remaining 2 had GBM. The patient with aneurysm underwent clipping, the one with vertebral artery dissection underwent bypass and we had one patient with Chiari malformation who required having extensive lateral drilling (Table 4; Figure 4).

Table 4: Patients distribution among each group.

\begin{tabular}{|c|c|c|}
\hline Group & Frequency & Percent \\
\hline Primary group & 89 & $96.70 \%$ \\
\hline Subsequent group & 3 & $3.30 \%$ \\
\hline Total & 92 & $100 \%$ \\
\hline
\end{tabular}

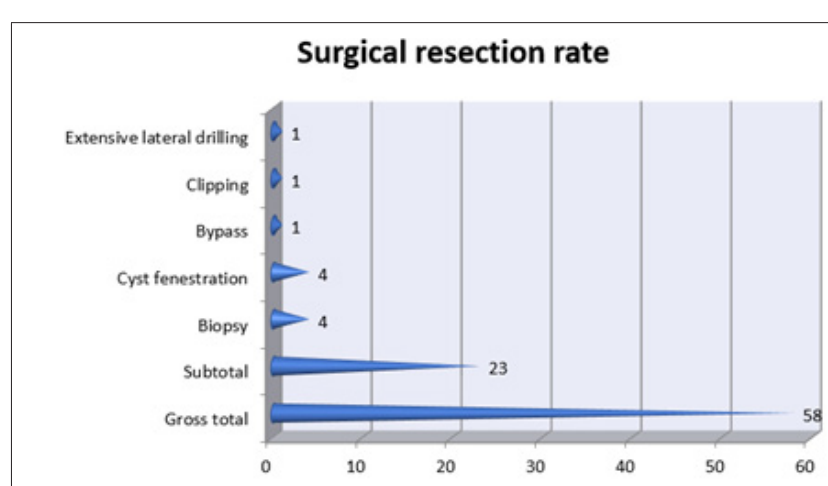

Figure 4: Surgical resection rate among all patients.

\section{Surgical approach}

Table 5: Surgical resection rate among all patients.

\begin{tabular}{|c|c|c|}
\hline Surgical Resection Rate & Frequency & Percent \\
\hline Gross total resection & 58 & $63 \%$ \\
\hline Subtotal resection & 23 & $25 \%$ \\
\hline Biopsy & 4 & $4.30 \%$ \\
\hline Cyst fenestration & 4 & $4.30 \%$ \\
\hline Bypass & 1 & $1.10 \%$ \\
\hline Clipping & 1 & $1.10 \%$ \\
\hline Extensive lateral drilling & 1 & $1.10 \%$ \\
\hline Total & 92 & $100 \%$ \\
\hline
\end{tabular}

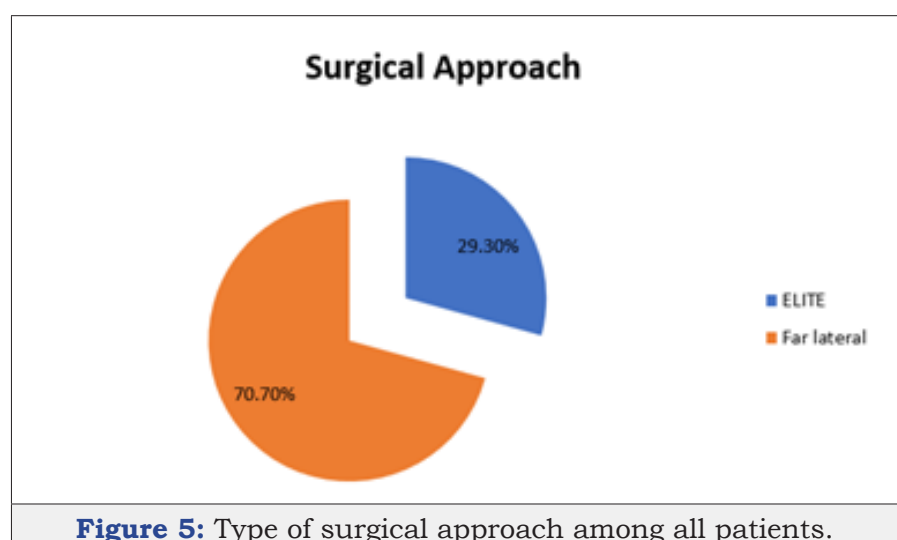

All patients in this study were approached either through far lateral or extreme lateral infra-jugular transchondylar approach (ELITE) (Table 5, Figure 5).

\section{Histopathology result}

Most patients were diagnosed with pilocytic astrocytoma (21 patients, 22.8\%) and medulloblastoma (19 patients, 20.7\%) (Table 6; Figure 6).

Table 6: Type of surgical approach among all patients.

\begin{tabular}{|c|c|c|}
\hline Surgical approach & Frequency & Percent \\
\hline ELITE & 27 & $29.30 \%$ \\
\hline Far lateral & 65 & $70.70 \%$ \\
\hline Total & 92 & $100 \%$ \\
\hline
\end{tabular}

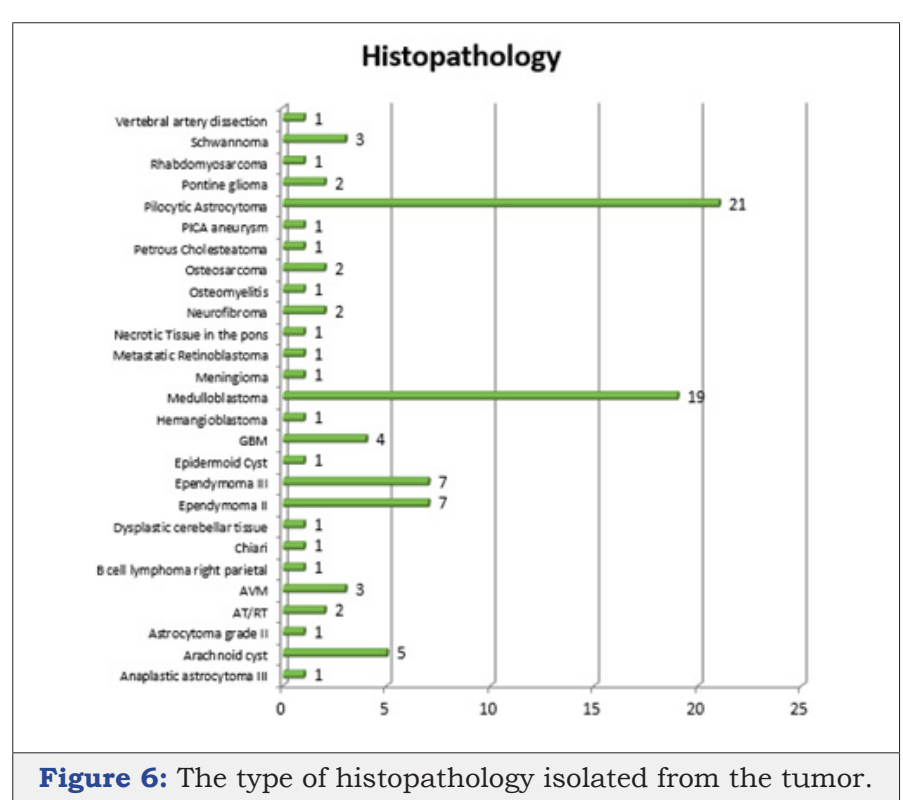

\section{Complications}

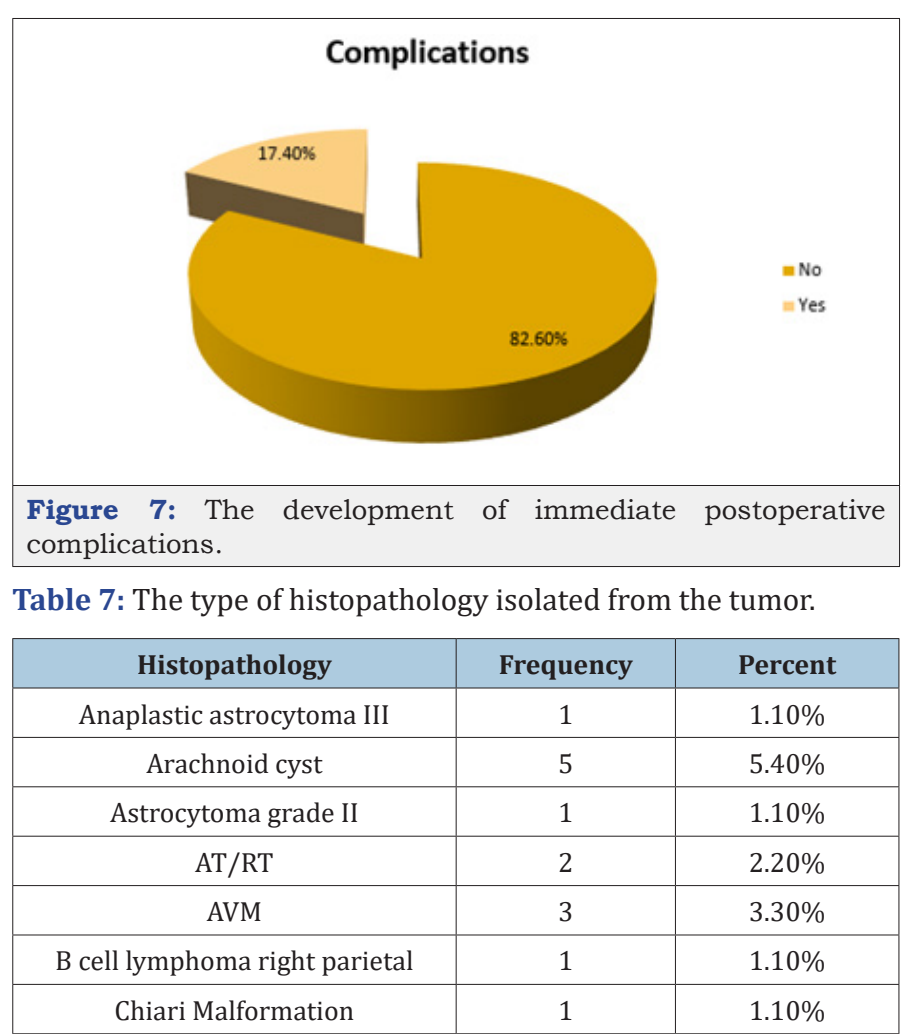




\begin{tabular}{|c|c|c|}
\hline Dysplastic cerebellar tissue & 1 & $1.10 \%$ \\
\hline Ependymoma II & 7 & $7.60 \%$ \\
\hline Ependymoma III & 7 & $7.60 \%$ \\
\hline Epidermoid Cyst & 1 & $1.10 \%$ \\
\hline GBM & 4 & $4.40 \%$ \\
\hline Hemangioblastoma & 1 & $1.10 \%$ \\
\hline Medulloblastoma & 19 & $20.70 \%$ \\
\hline Meningioma & 1 & $1.10 \%$ \\
\hline Metastatic Retinoblastoma & 1 & $1.10 \%$ \\
\hline Necrotic Tissue in the pons & 1 & $1.10 \%$ \\
\hline Neurofibroma & 2 & $2.20 \%$ \\
\hline Osteomyelitis & 1 & $1.10 \%$ \\
\hline Osteosarcoma & 2 & $2.20 \%$ \\
\hline Petrous Cholesteatoma & 1 & $1.10 \%$ \\
\hline PICA aneurysm & 1 & $1.10 \%$ \\
\hline Pilocytic Astrocytoma & 21 & $22.80 \%$ \\
\hline Pontine glioma & 2 & $2.20 \%$ \\
\hline Rhabdomyosarcoma & 1 & $1.10 \%$ \\
\hline Schwannoma & 3 & $3.30 \%$ \\
\hline Vertebral artery dissection & 1 & $1.10 \%$ \\
\hline Total & 92 & $100 \%$ \\
\hline
\end{tabular}

Table 8: The development of immediate postoperative complications.

\begin{tabular}{|c|c|c|}
\hline Complications & Frequency & Percent \\
\hline No & 76 & $82.60 \%$ \\
\hline Yes & 16 & $17.40 \%$ \\
\hline Total & 92 & $100 \%$ \\
\hline
\end{tabular}

Table 9: Postoperative complications among all patients.

\begin{tabular}{|c|c|}
\hline Type of Complications & Frequency \\
\hline CSF leak & 2 \\
\hline Died at ER later on & 1 \\
\hline Died at home & 2 \\
\hline Difficult breathing & 1 \\
\hline Developed venous fistula & 1 \\
\hline Posterior fossa abscess & 1 \\
\hline Pseudomeningocele & 2 \\
\hline Rebleed, PICA sacrifice on second surgery & 1 \\
\hline Respiratory failure & 1 \\
\hline Respiratory failure, then death & 2 \\
\hline Respiratory distress and CSF leak & 1 \\
\hline Secretions (excessive salivation), vocal paralysis \\
and vasovagal attack & 1 \\
\hline Seizures, pneumothorax & 1 \\
\hline Postoperative transient tachypnea & 1 \\
\hline Vascular injury, left SDH, pseudomeningocele & 1 \\
\hline
\end{tabular}

Only 16 patients $(17.4 \%)$ had postoperative complications. Most of them were manageable and transient while few were permanent and led to death). The neurologic complications were considered separately, 22 patients $(23.9 \%)$ had new neurological deficits immediately postoperatively (Tables 7-13; Figures 7-11).

Table 10: The development of new neurological deficit immediately postoperatively.

\begin{tabular}{|c|c|c|}
\hline New neurological deficits & Frequency & Percent \\
\hline No & 70 & 0.761 \\
\hline Yes & 22 & 0.239 \\
\hline Total & 92 & 1 \\
\hline
\end{tabular}

Table 11: Postoperative neurological deficits.

\begin{tabular}{|c|c|}
\hline Frequency & Type of neurological deficits \\
\hline 3 & CN VIII palsy \\
\hline 7 & CN VII Palsy \\
\hline 6 & CN VI palsy \\
\hline 1 & Convulsions \\
\hline 2 & Dysphagia \\
\hline 1 & upgaze palsy \\
\hline 7 & hemiparesis \\
\hline 1 & Hand flaccid paralysis \\
\hline 2 & vocal cord paralysis \\
\hline 2 & Impaired speech \\
\hline 1 & Minimal decrease in consciousness \\
\hline 3 & Mutism \\
\hline 1 & Quadriparesis \\
\hline 1 & blindness \\
\hline 1 & Lower CN (IX, X and XI) palsies \\
\hline 1 & Memory difficulty after RT \\
\hline
\end{tabular}

Table 12: the statistics of follow up period in months.

\begin{tabular}{|c|c|}
\hline Mean & 65.64 \\
\hline Median & 59 \\
\hline Mode & 97 \\
\hline Std. Deviation & 39.386 \\
\hline Minimum & 5 \\
\hline Maximum & 142 \\
\hline
\end{tabular}

Table 13: The final outcome among all patients approaches.

\begin{tabular}{|c|c|c|}
\hline Final Outcome & Frequency & Percent \\
\hline Cured & 56 & 0.609 \\
\hline Improved & 17 & 0.185 \\
\hline Deteriorated & 14 & 0.152 \\
\hline Recurrence & 1 & 0.011 \\
\hline Died & 4 & 0.043 \\
\hline Total & 92 & 1 \\
\hline
\end{tabular}

\section{Final Outcome}

The final outcome was categorized into 5 broad categories:

\section{Cured}

The patient was considered cured if the pathology was totally excised and didn't recur in a time period equivalent to patient's age at diagnosis plus 9 months "Collin's Law". 


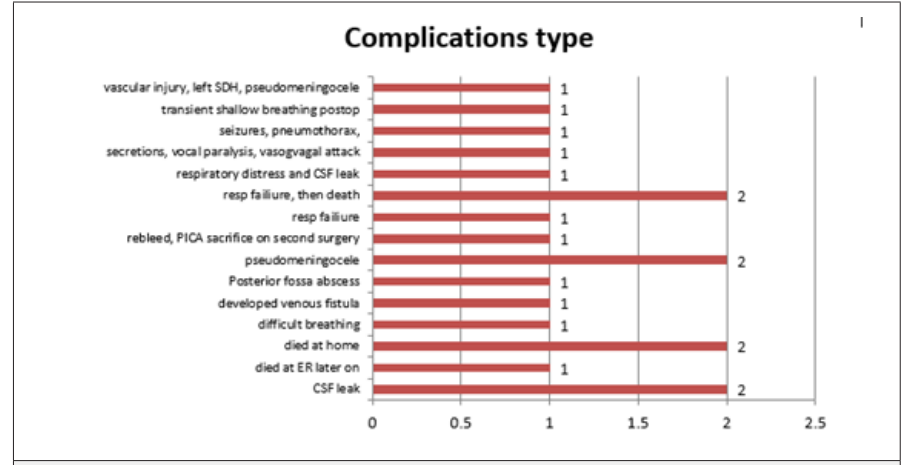

Figure 8: Postoperative complications among all patients.

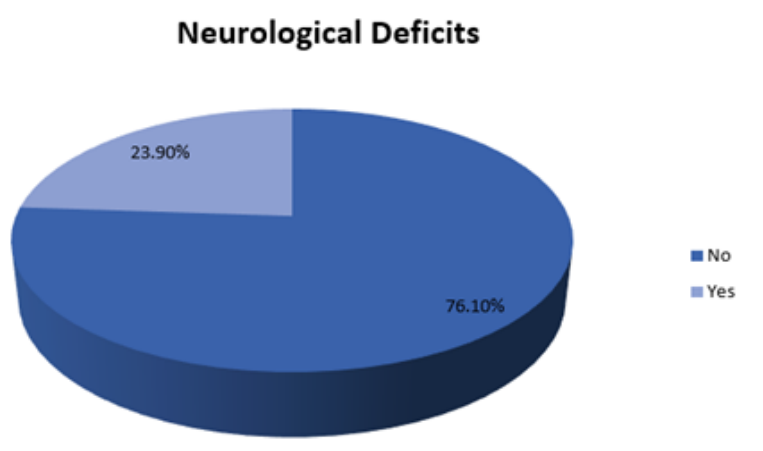

Figure 9: The development of new neurological deficit immediately postoperatively.

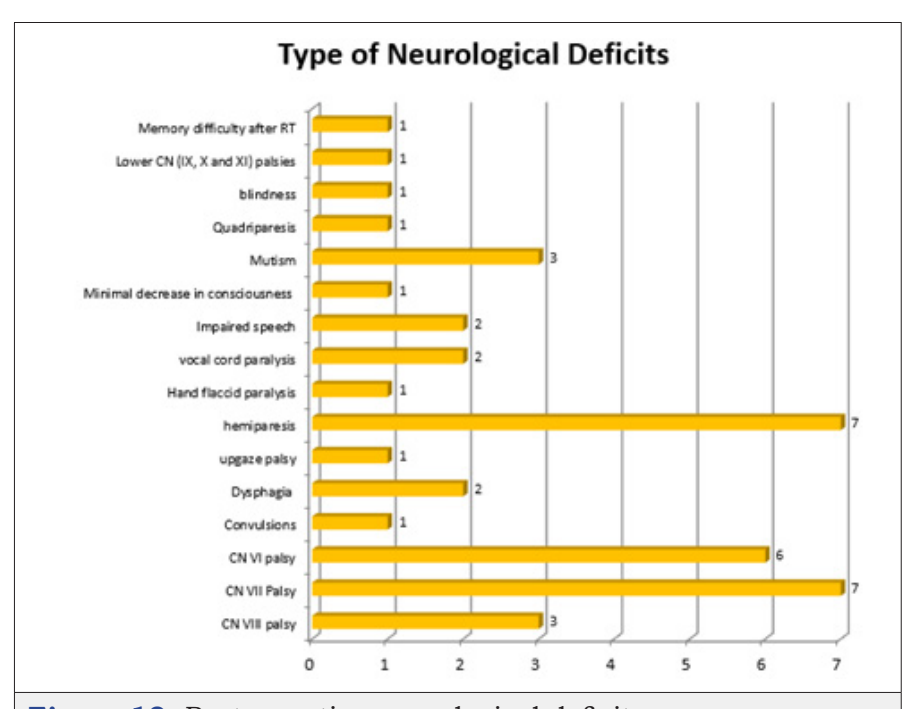

Figure 10: Postoperative neurological deficits.

\section{Improved}

a) If the patient had new neurological deficits postoperatively and completely resolved with time, or

b) In those patients in whom the tumor recurred and completely excised in the subsequent surgeries, or

c) Patients who were postoperatively diagnosed as highgrade malignancy that cannot be completely cured like GBM and pontine glioma.

Deteriorated: If patient had a new postoperative neurological deficit that remained static or got worse during the follow-up. Also, patients in whom tumor growth progressively increased during follow-up after subtotal resection. Recurrence: Any patient who underwent gross total resection, but the tumor recurred during the follow-up period. Died: Patients who died postoperatively, soon after discharge or during the follow-up period. Tumor recurrence occurred in one patient; histopathology revealed anaplastic astrocytoma WHO grade III. Among the 4 patients who died: 3 of them had a high-grade tumor (osteosarcoma, anaplastic Ependymoma WHO grade III and Medulloblastoma WHO grade IV) while one had benign pilocytic astrocytoma WHO grade I. Two of them died at home and 2 of them died in the hospital (one of them postoperatively due to respiratory failure and the other in the ER later during follow up).

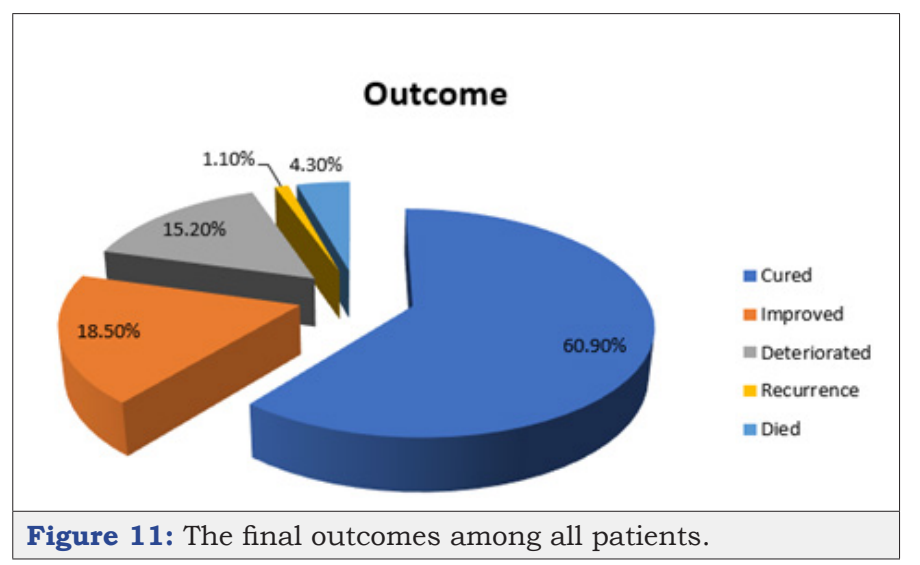

\section{Discussion}

Far lateral approach or extreme lateral approach was early described and utilized for several foramen magnum tumors and vascular malformations anterior and anterolateral to the brain stem since the 1980s. As Rady Children's hospital is a pediatric hospital, most patients included in this study were children but we had referred difficult adult cases from time to time to our center from Mexico and other places in USA. Most of the pathologies in the literature which were approached through this approach were meningiomas, neurofibromas, and vascular malformations (like glomus jugulare, aneurysms and AVMs). However in this study we operated upon wide range of pathologies including astrocytoms with different grades, arachnoid cysts, AT/RT,lymphomas, ependymomas, neurofibromas, epidermoid cysts, hemangiomas, meningiomas, medulloblastomas, mets, osteosarcoma, cholesteatoma, Rhabdomysarcoma, aneurysms and vertebral artery dissection. This approach was found to be useful for primary as well as recurrent pathologies in which the conventional posterior fossa approach failed for the reason that by removing only small part of the bone you can easily resect most of the lesions without doing much retraction to the brainstem. In this study we operated upon some recurrent pathologies using this approach. Besides that, this approach enables complete removal of pathologies lateral and ventrolateral to thr brainstem. In this study gross total resection was achieved in more than half of the patients. The complications of this approach include lower cranial nerve palsies, quadriparesis, injury to the PICA22 and CSF leak22. We encountered most of these complications in this study in little number of cases and most of the complications encountered were transient and resolved few months after surgery while few of the complications were related 
to the radiotherapy and not to the surgery. Follow up of the patients should be done for a quite long period to ensure complete recovery, no recurrences and no further surgical intervention is needed.

\section{Conclusion}

Far lateral approach or Extreme Lateral Transchondylar approach provides safe trajectory to most posterior skull base lesions located lateral or venterolateral to the brainstem. This includes wide range of benign, malignant as well as vascular malformations. The complications related to this approach are the same if not less than those described for other approaches to lesions in this area with the added benefits of complete resectability, less postoperative cranial nerve palsies and hence less need for postoperative adjuvant therapy for benign, deeply seated, non resectable pathologies. This also ensures less recurrence rates after surgical resection, favorable outcome and long-term survival for most of the patients. This approach can be effective for children as well as adults harboring difficult posterior fossa pathologies with less postoperative mortalities and morbidities.

\section{References}

1. Cavalheiro S, Yagmurlu K, Da Costa MD (2015) Surgical approaches for brainstem tumors in pediatric patients. Childs Nerv Syst 31(10): 18151840 .

2. Heros RC (1986) Lateral suboccipital approach for vertebral and vertebrobasilar artery lesions. J Neurosurg 64(4): 559-562.

3. Rohde V, Schaller C, Hassler W (1994) The extreme lateral transcondylar approach to aneurysms of the vertebrobasilar junction, the vertebral artery, and the posterior inferior cerebellar artery. Skull Base Surg 4(4): 177-180.

4. George B, Dematons C, Cophignon J (1988) Lateral approach to the anterior portion of the foramen magnum. Application to surgical removal of 14 benign tumors: technical note. Surg Neurol 29(6): 484-490.

5. Sen CN, Sekhar LN (1990) An extreme lateral approach to intradural lesions of the cervical spine and foramen magnum. Neurosurgery $27(2)$ 197-204.

6. Kratimenos GP, Crockard HA (1993) The far lateral approach for ventrally placed foramen magnum and upper cervical spine tumours. Br J Neurosurg 7(2): 129-140.

7. Vishteh AG, David CA, Marciano FF, Coscarella E, Spetzler RF (2000) Extreme lateral supracerebellar infratentorial approach to the posterolateral mesencephalon: technique and clinical experience. Neurosurgery 46(2): 384-388.

8. Patel AJ, Gressot LV, Cherian J, Desai SK, Jea A (2014) Far lateral paracondylar versus transcondylar approach in the pediatric age group: CT morphometric analysis. J Clin Neurosci 21(12): 2194-2200.
9. Patel SK, Liu JK (2013) Staged bilateral far-lateral approach for bilateral cervicomedullary junction neurenteric cysts in a 10-year-old girl. J Neurosurg Pediatr 12(3): 274-280.

10. Menezes AH (2008) Surgical approaches: postoperative care and complications posterolateral-far lateral transcondylar approach to the ventral foramen magnum and upper cervical spinal canal. Childs Nerv Syst 24(10): 1203-1207.

11. Brockmeyer D, Gruber DP, Haller J, Shelton C, Walker ML (2003) Pediatric skull base surgery experience and outcomes in 55 patients. Pediatr Neurosurg 38(1): 9-15.

12. Markert JM, Chandler WF, Deveikis JP, Ross DA (1996) Use of the extreme lateral approach in the surgical treatment of an intradural ventral cervical spinal cord vascular malformation: technical case report. Neurosurgery 38: 412-415.

13. Day JD, Fukushima T, Giannotta SL (1997) Cranial base approaches to posterior circulation aneurysms. J Neurosurg 87(4): 544-554.

14. Liu JK, Couldwell WT (2005) Far lateral transcondylar approach: surgical technique and its application in neurenteric cysts of the cervicomedullary junction. Report of two cases. Neurosurg Focus 19(2): E9.

15. Patel SJ, Sekhar LN, Cass SP, Hirsch BE (1994) Combined approaches for resection of extensive glomus jugulare tumors. A review of 12 cases. J Neurosurg 80(6): 1026-1038.

16. Banerji D, Behari S, Jain VK, Pandey T, Chhabra DK (1999) Extreme lateral transcondylar approach to the skull base. Neurol India 47(1): 22-30.

17. Kumar CV, Satyanarayana S, Rao BR, Palur RS (2001) Extreme lateral approach to ventral and ventrolaterally situated lesions of the lower brainstem and upper cervical cord. Skull Base 11(4): 265-275.

18. Menezes AH (2008) Surgical approaches: postoperative care and complications posterolateral-far lateral transcondylar approach to the ventral foramen magnum and upper cervical spinal canal. Childs Nerv Syst 24: 1203-1207.

19. Liu JK (2012) Extreme lateral transcondylar approach for resection of ventrally based meningioma of the craniovertebral junction and upper cervical spine. Neurosurg Focus 33(1): 1.

20. Park HH, Lee KS, Hong CK (2016) Vertebral artery transposition via an extreme-lateral approach for anterior foramen magnum meningioma or craniocervical junction tumors. World Neurosurg 88: 154-165.

21. Lawton MT, Daspit CP, Spetzler RF (1997) Technical aspects and recent trends in the management of large and giant midbasilar artery aneurysms. Neurosurgery 41(3): 513-520.

22. Calayag M, Gabel BC, Hong DS (2016) 197 Considerations in relationship to the approach for the treatment of lateralized posterior fossa tumors in children. Neurosurgery 63(1): 177-178. 